\title{
Non-operative management of blunt hepatic and splenic injury: a time-trend and outcome analysis over a period of 17 years
}

Margot Fodor ${ }^{1 \dagger}$, Florian Primavesi ${ }^{1 \dagger}$, Dagmar Morell-Hofert ${ }^{2}$, Veronika Kranebitter ${ }^{1}$, Anna Palaver ${ }^{1}$, Eva Braunwarth ${ }^{1}$, Matthias Haselbacher ${ }^{3}$, Ulrich Nitsche ${ }^{4}$, Stefan Schmid ${ }^{5}$, Michael Blauth ${ }^{3}$, Eva Gassner², Dietmar Öfner ${ }^{1}$ and Stefan Stättner ${ }^{1 *}$ (ID

\begin{abstract}
Background: A widespread shift to non-operative management (NOM) for blunt hepatic and splenic injuries has been observed in most centers worldwide. Furthermore, many countries introduced safety measures to systematically reduce severe traffic and leisure sports injuries. This study aims to evaluate the effect of these nationwide implementations on individual patient characteristics and outcomes through a time-trend analysis over 17 years in an Austrian high-volume trauma center.

Methods: A retrospective review of all emergency trauma patients admitted to the Medical University of Innsbruck from 2000 to 2016. Injury severity, clinical data on admission, operative and non-operative treatment parameters, complications, and in-hospital mortality were evaluated.

Results: In total, 731 patients were treated with blunt hepatic and/or splenic injuries. Among these, 368 had a liver injury, 280 splenic injury, and 83 combined hepatic/splenic injury. Initial NOM was performed in $82.6 \%$ of all patients (93.5\% in hepatic and $71.8 \%$ in splenic injuries) with a success rate of $96.7 \%$. The secondary failure rate of NOM was $3.3 \%$ and remained consistent over 17 years $(p=0.515)$. In terms of injury severity, we observed a reduction over time, resulting in an overall mortality rate of $4.8 \%$ and $3.5 \%$ in the NOM group (decreasing from 7.5 to $1.9 \%$ and from 5.6 to $1.3 \%$, respectively). These outcomes confirmed an improved utilization of the NOM approach.

Conclusion: Our cohort represents one of the largest Central European single-center experiences available in the literature. NOM is the standard of care for blunt hepatic and splenic injuries and successful in $>96 \%$ of all patients. This rate was quite constant over 17 years $(p=0.515)$. Overall, national and regional safety measures resulted in a significantly decreased severity of observed injury patterns and deaths due to blunt hepatic or splenic trauma. Although surgery is nowadays only applied in about one third of splenic injury patients in our center, these numbers might further decrease by intensified application of interventional radiology and modern coagulation management.
\end{abstract}

Keywords: Blunt abdominal trauma, Non-operative management, Safety measures

\footnotetext{
*Correspondence: stefan.staettner@i-med.ac.at

${ }^{\dagger}$ Margot Fodor and Florian Primavesi contributed equally to this work.

'Department of Visceral, Transplantation and Thoracic Surgery, Center of

Operative Medicine, Medical University of Innsbruck, Anichstraße 35, 6020

Innsbruck, Austria

Full list of author information is available at the end of the article
}

C The Author(s). 2019 Open Access This article is distributed under the terms of the Creative Commons Attribution 4.0 International License (http://creativecommons.org/licenses/by/4.0/), which permits unrestricted use, distribution, and reproduction in any medium, provided you give appropriate credit to the original author(s) and the source, provide a link to the Creative Commons license, and indicate if changes were made. The Creative Commons Public Domain Dedication waiver (http://creativecommons.org/publicdomain/zero/1.0/) applies to the data made available in this article, unless otherwise stated. 


\section{Background}

Compared to penetrating injuries, blunt abdominal trauma is very common in central European emergency departments. The management of these injuries can be complex because of frequent association with a multifaceted picture of trauma, involving head, thoracic, and limb injuries [1]. Abdominal organs are involved in approximately $30 \%$ of polytrauma patients, with the occurrence of hepatic and splenic injuries in 13 and 16\%, respectively [2]. Many technical advances in medicine allow to better diagnose and treat these kinds of injuries both with surgery or nonoperative management (NOM), the latter usually also including radiological interventions [3-5].

Currently, NOM is the standard of care in hemodynamically stable patients [6], which is associated with an estimated success rate exceeding 80-90\% [2]. NOM has been described as a safe procedure when availability of experienced surgeons, modern imaging modalities, intensive care units (ICU), and other supporting services is assured [7]. While NOM carries the risk of missed hollow visceral injuries or delayed bleeding, operative management $(\mathrm{OM})$ is naturally associated with the possible side effects of any surgical intervention, depending on a variety of patient, medical, and technical factors. In practice, the choice between NOM or OM is mainly driven by hemodynamic considerations rather than the severity of organ injury [8-12]. NOM enables reduction of non-therapeutic laparotomies with potential intra-abdominal complications and unnecessary transfusion risks, thereby resulting in overall lower costs and decreased morbidity and mortality compared to OM [2, 11, 12]. While the benefits of NOM are unquestionable, there is still a lack of consensus regarding patient stratification and potential risk factors for inapplicability or failure of NOM. Strong evidence exists that an age of 40 years or above, Injury Severity Score (ISS) of 25 or greater, associated intra-abdominal injuries and hepatic/ splenic injury grade III or higher are prognostic factors for failure of NOM $[6,7,9,13]$.

Regarding the burden of severe injuries, within the last decades, many governments, insurance companies, and automobile clubs in Austria and other European countries introduced a number of measures to improve traffic and sports safety. Examples for preventive traffic measures include nationwide driving license obligations, penalization systems for driving under influence of alcohol and other substances, systematic control of speeding, and compulsory use of helmets for motorcycle drivers and car seat belts especially for children. Concurrent increasing technical standards in the car industry including the development of airbags and driver assistance systems markedly improved safety for traffic participants. Also, across many different types of leisure sports, major efforts were taken, e.g., by introduction of head protection gear in aerial, cycling, and winter sports activities [14], to increase safety.

Overall, in the European Union (EU), the number of fatal road crashes decreased by $43 \%$ between 2000 and 2010, by another 20\% from 2011 to 2017. In this regard, the EU is the world's safest region with 49 deaths per million inhabitants due to road collisions. However, the safety conditions differ widely between individual member states [15]. In line with the general European trend, also in Austria, fewer road collisions were registered in the last decade. As shown in Fig. 1a, while the number of traffic collisions from 2002 to 2016 in our country decreased by only $10.9 \%$ and the number of injured people by $14.6 \%$, traffic deaths could substantially be reduced by $54.8 \%$. The current rate of road deaths/injuries of $0.88 \%$ represents the lowest level since the initiation of statistical recording in 1961. In contrast, concerning recreational, sports and homely environment injuries, the number of injured people could not be decreased over the last years in our country (Fig. 1b). Although the death rate is slowly declining also in these types of accidents, some activities such as winter sports are associated with a certain injury risk $[14,16,17]$. Compared to about 8 million skiers and snowboarders visiting the Austrian Alps annually, the mean injury rate is low, at less than 2 injuries per 1000 skier days [17]. However, in 2016, a total of 52.100 winter sports injuries including 40 deaths were registered [14]. Accordingly, national safety bodies have recently stated again that nationwide safety measures have been successfully implemented first and foremost in traffic environment while a comparable effort could not be achieved in another type of injuries so far [18]. Overall, the influence of these national actions on the type and severity of trauma in individual patients and outcomes in specialized centers remains indeterminate.

The objective of this study therefore was to examine the prevalence, clinical presentation, management, and outcomes of OM and NOM of blunt hepatic and splenic injuries over a time span of 17 years at a large tertiary referral center situated in a characteristic central European alpine area in Western Austria.

\section{Methods}

All patients presenting with traumatic blunt hepatic and/or splenic injury to Medical University of Innsbruck from January 1, 2000, to December 31, 2016, were included. Our prospectively maintained and auditable primary patient's database was retrospectively screened for detailed data about blunt hepatic/splenic injuries from the patients' medical records and imaging files. To record for consecutive changes in the management of blunt hepatic/splenic trauma (details of patient characteristics, surgical and conservative management, and short-term patient outcome) two comparable distributed subperiods 


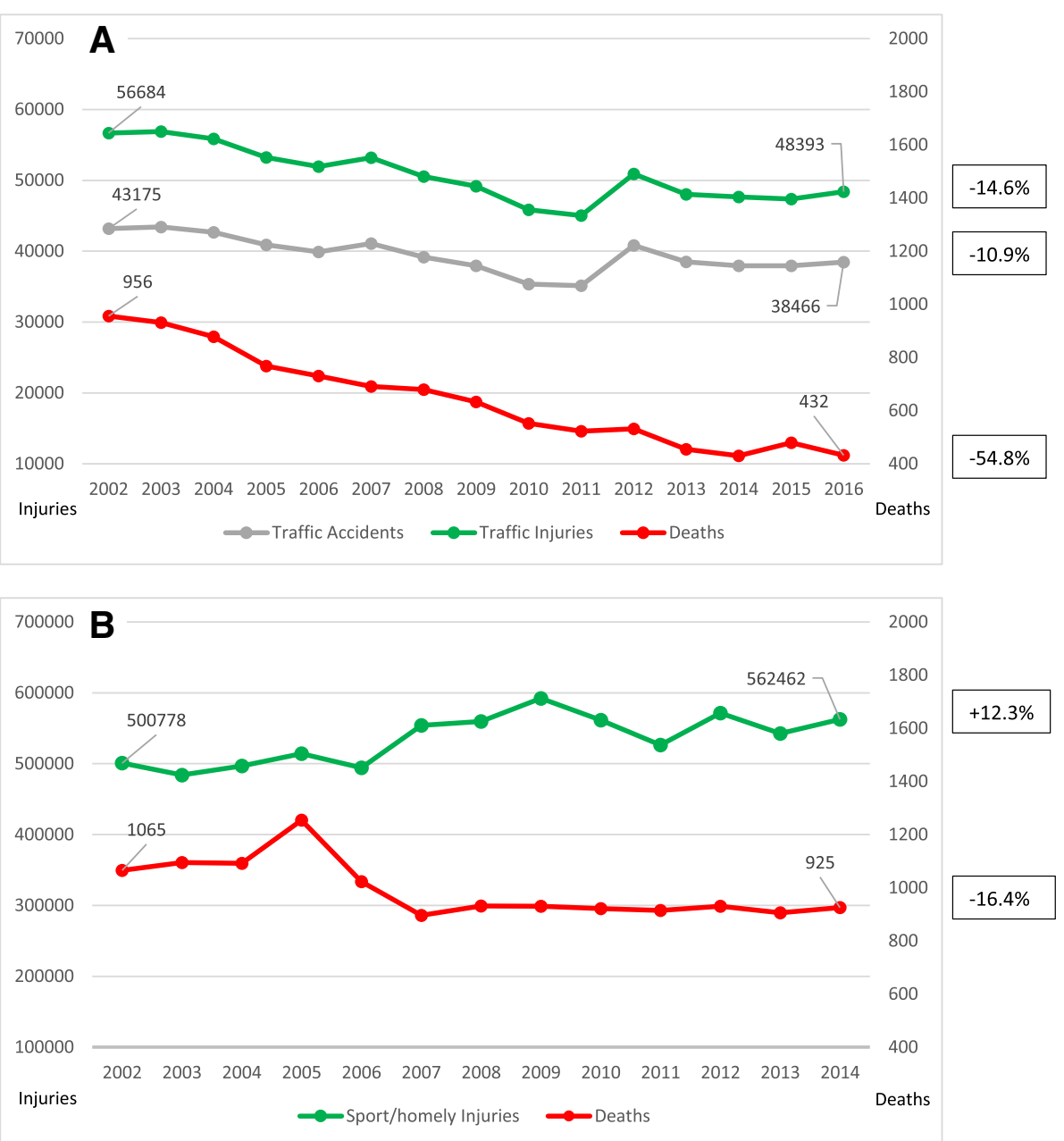

Fig. 1 a National numbers of road traffic accidents (gray), injured people (green), and deaths (red) in Austria between 2002 and 2016 according to Statistics Austria National Data [14]. b Estimated national recreational and sports injuries in Austria from 2002 to 2014 (green) according to the European Injury Database [16]. Road accidents, paid-work accidents, assaults, intentional self-harm, poisoning, and thermal injuries (burn/scald) are excluded. Red: deaths after recreational or sports injuries in Austria according to Statistics Austria National Data [14]

were compared (2000-2008, 2009-2016). Patients who sustained penetrating abdominal injuries and those who were declared dead during transfer to our hospital and were not receiving cardiopulmonary resuscitation (CPR) on arrival were excluded. Patients that were actively treated with fluid or mechanical resuscitation when arriving at our center were included even when no return of spontaneous circulation (ROSC) occurred during further emergency room treatment. Previous external surgical or interventional procedures prior to initial radiographic assessment at our institution were also considered an exclusion criterion, while patients immediately transferred to our center from district hospitals after receiving only diagnostics were included in the analysis. A standardized emergency care protocol is used to manage trauma cases at our center. Focused Assessment with Sonography for Trauma (FAST) is utilized in the early assessment of all patients to detect the presence or absence of hemoperitoneum. Depending on initial assessment, suspected concomitant injuries and X-ray as well as sonography findings, selective abdominal/thoracic/cranial or whole body dual or triple phase CT scan is performed in all hemodynamically stable patients according to a designated protocol. In patients with hemodynamic instability or cases with contraindication for contrast due to severe iodine allergy or poor renal function, sonographic or noncontrast-enhanced CT-assessment was chosen as first assessment. Initial treatment in all patients includes thrombelastography-guided coagulation management according to national guidelines [19], primarily based on individual coagulation factor and fibrinogen substitution, avoidance of fresh frozen plasma, and thrombocyte transfusion when possible and early detection and treatment of deleterious hyperfibrinolysis as previously described by 
our group [20]. Fluid resuscitation is performed with a balanced combination of crystalloid and colloidal infusions. The trigger level for transfusion of red blood cell and thrombocyte packs has been continuously adapted over the years, currently ranging at a cutoff of $8 \mathrm{~g} / \mathrm{dl}$ hemoglobin and $100,000 / \mu \mathrm{l}$ thrombocytes, respectively, in our center.

For this study, all CT images were re-evaluated regarding injury grading by two trained radiologists, with a combined clinical experience of $>30$ years, blinded to the initial CT result and the clinical outcome. For each patient, 3.5 to $5 \mathrm{~mm}$-thick transversal and $5 \mathrm{~mm}$-thick sagittal and coronal multiplanar-reformatted images were reviewed on a picture archiving and communication system (AGFA IMPAX; AGFA Health Care, Greenville, SC). Divergent findings were jointly assessed, and final results being decided by consensus. Cases in which no lesion was found on radiologic evaluation, with non-existing trauma history (e.g., spontaneous splenic rupture) or with substantially missing information in medical records, were not included in the analysis. For patients with sole sonographic imaging, CT-equivalent injury grading was recorded (all had minor injuries). Blunt hepatic and splenic lesions were classified by the 1994 revision of the AASTMoore-Classification system (Additional file 1: Table S1 and Additional file 2: Table S2) [21].

The following clinical parameters were collected for this study: patient age and gender, trauma cause, accompanying injuries type and severity, Glasgow Coma Score (GCS), routine laboratory studies, and initial vital parameters. Furthermore, initial trauma management (operative vs. non-operative), type of (N)OM, management complications, failure rate of NOM and underlying failure cause, treatment of complications, total length of hospital stay (LOS), in-hospital mortality, and cause of death were documented. Failure of NOM was defined as the need for operation due to ongoing bleeding from the liver/spleen or other indications for surgery (e.g., abscess, peritonism). ERCP or angiographic interventions were considered as NOM. For each patient, individual injuries were retrospectively classified by body region and by relative severity on a 6-point-scale, according to the latest update (2008) [22] of the Abbreviated Injury Score (AIS) 2005 by the American Association for Automotive Medicine (AAAM) [23]. Injury Severity Scores (ISS) were then calculated upon adding AIS for multiple injured patients [24]. Variables necessary for the Revised Trauma Injury Score (RTS) on admission were not retrospectively available in about half of the patients; thus, this classification was not included in the analysis. The study protocol was approved by the institutional medical review board (protocol-number EK 1034/2017), which waived the need for informed consent due to the retrospective design. The reporting of this study conforms to the STROBE guidelines [25].

\section{Statistical analysis}

Data were presented as proportions (\%), means \pm standard deviation (SD), or medians as appropriate. Differences between time-periods were determined using the $X^{2}$ and Fisher's Exact Test for categorical variables and the $T$ test or Mann-Whitney $U$ test for continuous variables depending on the normal distribution, which was assessed with Shapiro-Wilk test. Two-tailed $p$ values less than 0.05 were considered significant throughout the analysis. Data analysis was carried out using SPSS 21.0 (IBM Corporation, Armonk, NY, USA).

\section{Results}

\section{Patient characteristics}

Between 2000 and 2016, 814 patients were admitted to our hospital with suspected blunt hepatic or splenic injury (Fig. 2). After exclusion of cases without a history of trauma or without clinical, intraoperative, or radiological confirmation of liver or spleen involvement, a total of 731 patients were included in the final analysis, resulting in a mean of 43 cases per year. Table 1 shows patient characteristics in the whole study period and the differences over time between the early group (2000-2008) and late group (2009-2016). The number of cases with blunt abdominal injuries to the liver and/or spleen was comparable in both periods $(n=372$ versus $n=359)$, as was in demographic details. However, clinical factors and laboratory findings associated with severity of trauma were markedly different. Patients injured before 2009 showed a significantly lower mean GCS score and higher ISS score (both $p<0.001$ ). Concurrently, the rate of patients unconscious on arrival $(\mathrm{GCS} \leq 8)$ decreased significantly (20.7 to $8.6 \%$ ), as did cases with polytrauma (defined as ISS $>15$, 90.9 to $79.1 \%$, both $p<0.001$ ). The mean ISS values were lower during the recent period in both operatively and non-operatively managed patients $(p<0.001)$.

\section{Injury details}

Details of trauma characteristics, involving organs and severity of liver and spleen injury according to AAST classification are depicted in Table 2. Concerning the mechanisms of injury, also significant changes over the two periods could be shown $(p<0.001)$. While previously traffic incidents involving a car, motorcycle, and pedestrian collision were accounting for $46.7 \%$ of injuries, these declined to $29.2 \%$ in recent years. Simultaneously, winter sport and cycling collision were increasing from 31.4 to $52.4 \%$. Other causes of trauma included fall from heights, horse riding collision, minimal trauma (mostly in homely environment), and exceptionally rarely personal assault. As a result, in terms of involved organs, combined liver and spleen injury decreased significantly from 15.3 to $7.2 \%$, with a concurrent rise in isolated splenic trauma (33.1 to $43.7 \%, p=0.001$ ). 


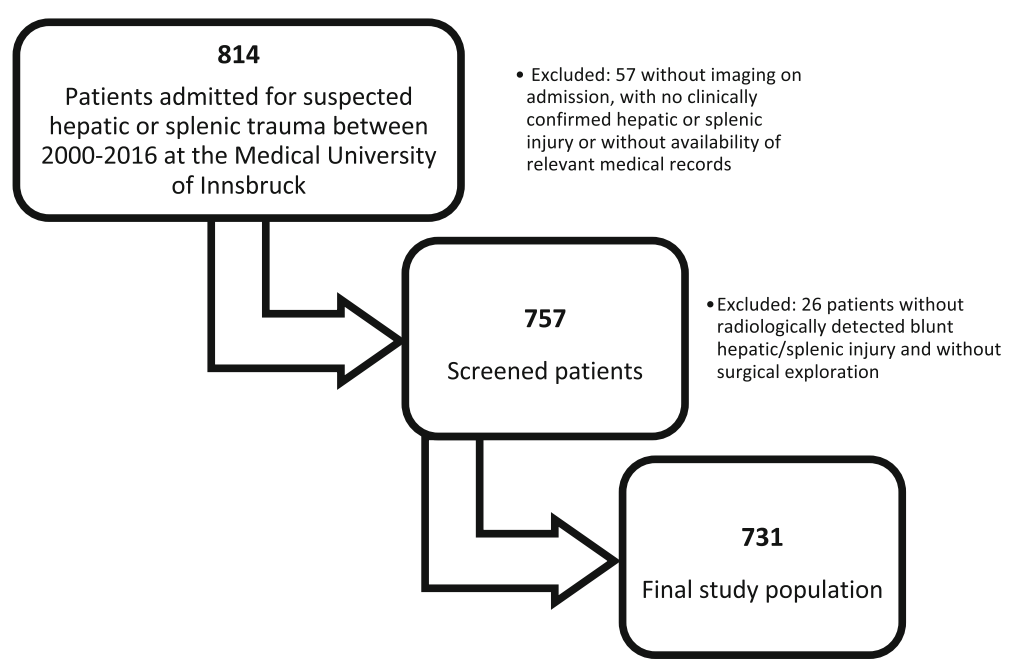

Fig. 2 Patient selection chart

Overall, the cohort included 280 splenic, 368 liver, and 83 combined liver and spleen injuries.

Regarding grading according to the AAST classification, in the early period, $54.2 \%$ of patients had minor liver trauma (AAST I-III) and 37.9\% minor spleen trauma versus $45.8 \%$ and $39.4 \%$ in the late period, respectively.

Concerning extra-abdominal injuries, all body regions except face were significantly less often involved over the analyzed time span (each $p<0.001$ ).

\section{Management of trauma patients (Table 3 )}

One hundred twenty-seven (17.4\%) patients underwent immediate surgery, with no significant change over time $(p=0.393)$. Complete splenectomy was performed in 79 (10.8\%) patients, while spleen-preserving procedures were applied in 17 (2.3\%) cases. Liver resection was performed in $8(1.1 \%)$ patients, liver-conserving procedures were sufficient in $34(4.7 \%)$ patients (suture $n=16$, hemostasis $n=10$, packing $n=8$ patients).

In contrast, $604(82.6 \%)$ patients underwent initial non-operative treatment, with a total of 344 hepatic (93.5\%), 201 splenic (71.8\%), and 59 combined injuries (71.1\%) being managed non-operatively. Also, no significant differences were noted over time.

In all patients undergoing primary OM, hemodynamic instability was persistent despite appropriate resuscitation measures (as described in the "Methods" section), and instability therefore was the primary indication for surgery. Associated radiological or laboratory findings recorded (multiple possible) were high organ-specific injury score ( $n=36,28.4 \%)$, involvement of multiple abdominal organs ( $n=46,36.2 \%)$, extensive hemoperitoneum $(n=34$, $26.8 \%)$, substantial drop in hemoglobin with need for massive transfusion $(n=33,26 \%)$, and marked extravasation of contrast media on CT $(n=13,10.2 \%)$. In 47

Table 1 Patient characteristics and admission values

\begin{tabular}{|c|c|c|c|c|}
\hline & $\begin{array}{l}\text { Overall cohort (2000-2016) } \\
n=731\end{array}$ & $\begin{array}{l}\text { Early period (2000-2008) } \\
n=372\end{array}$ & $\begin{array}{l}\text { Late period (2009-2016) } \\
n=359\end{array}$ & $\begin{array}{l}\text { Difference between periods } \\
P\end{array}$ \\
\hline Male & $497(68 \%)$ & $251(67.5 \%)$ & $246(68.5 \%)$ & 0.761 \\
\hline Age (mean, SD) & $32.4(18.1)$ & $31.8(17.8)$ & $33.1(18.4)$ & 0.318 \\
\hline \multicolumn{5}{|l|}{ GCS on admission (missing $=15$ ) } \\
\hline Mean (SD) & $13.02(3.57)$ & $12.46(3.9)$ & $13.60(3.1)$ & $<0.001$ \\
\hline $\mathrm{GCS} \leq 8$ & $106(14.8 \%)$ & $76(20.7 \%)$ & $30(8.6 \%)$ & $<0.001$ \\
\hline \multicolumn{5}{|l|}{ Injury Severity Score } \\
\hline Median (range) & $27(4-75)$ & $33(4-75)$ & $24(4-65)$ & $<0.001$ \\
\hline > 15 (definition of polytrauma) & $622(85.1 \%)$ & $338(90.9 \%)$ & $284(79.1 \%)$ & $<0.001$ \\
\hline Mean (SD) NOM patients & $26.7(12.35)$ & $29.3(12.24)$ & $24.1(11.92)$ & $<0.001$ \\
\hline Mean (SD) OM patients & $31.5(13.86)$ & 35.8 (12.39) & $26.3(13.84)$ & $<0.001$ \\
\hline
\end{tabular}

GCS Glasgow Coma Scale, SD standard deviation, NOM non-operative management, OM operative management 
Table 2 Trauma characteristics

\begin{tabular}{|c|c|c|c|c|}
\hline & $\begin{array}{l}\text { Overall cohort (2000-2016) } \\
n=731\end{array}$ & $\begin{array}{l}\text { Early period (2000-2008) } \\
n=372\end{array}$ & $\begin{array}{l}\text { Late period (2009-2016) } \\
n=359\end{array}$ & $\begin{array}{l}\text { Difference between periods } \\
P\end{array}$ \\
\hline \multicolumn{5}{|l|}{ a. Trauma mechanism injury data } \\
\hline \multicolumn{5}{|l|}{ Trauma cause (missing $=2$ ) } \\
\hline Car collision & $156(21.4 \%)$ & $101(27.3 \%)$ & $55(15.3 \%)$ & \multirow[t]{9}{*}{$<0.001$} \\
\hline Motorcycle collision & $87(11.9 \%)$ & $46(12.4 \%)$ & $41(11.4 \%)$ & \\
\hline $\begin{array}{l}\text { Pedestrian or comparable } \\
\text { occupational collision }\end{array}$ & $35(4.8 \%)$ & $26(7 \%)$ & $9(2.5 \%)$ & \\
\hline Cycling collision & $62(8.5 \%)$ & $24(6.5 \%)$ & $38(10.6 \%)$ & \\
\hline Winter sports & $242(33.2 \%)$ & $92(24.9 \%)$ & $150(41.8 \%)$ & \\
\hline Fall from heights & $76(10.4 \%)$ & 49 (13.2\%) & $27(7.5 \%)$ & \\
\hline Trauma in homely environment & $47(6.4 \%)$ & $20(5.4 \%)$ & $27(7.5 \%)$ & \\
\hline Personal assault & $3(0.4 \%)$ & $1(0.3 \%)$ & $2(0.6 \%)$ & \\
\hline $\begin{array}{l}\text { Horse riding collision (and other } \\
\text { animal associated injuries) }\end{array}$ & $21(2.9 \%)$ & $11(3.0 \%)$ & $10(2.8 \%)$ & \\
\hline \multicolumn{5}{|l|}{ b. Organ injury data } \\
\hline \multicolumn{5}{|l|}{ Injured organ } \\
\hline Spleen & $280(38.3 \%)$ & $123(33.1 \%)$ & $157(43.7 \%)$ & \multirow[t]{3}{*}{0.001} \\
\hline Liver & $368(50.3 \%)$ & $192(51.6 \%)$ & $176(49 \%)$ & \\
\hline Combined liver and spleen injury & $83(11.4 \%)$ & $57(15.3 \%)$ & $26(7.2 \%)$ & \\
\hline \multicolumn{5}{|l|}{$\begin{array}{l}\text { AAST (Moore) Injury Score (according } \\
\text { to admission CT scan; no } C T, n=9 \text { ) }\end{array}$} \\
\hline \multicolumn{5}{|l|}{ Spleen } \\
\hline No spleen injury & $367(50.8 \%)$ & $192(52.7 \%)$ & $175(48.9 \%)$ & \multirow[t]{6}{*}{0.008} \\
\hline । & $40(5.5 \%)$ & $22(6 \%)$ & $18(5 \%)$ & \\
\hline$\|$ & $66(9.1 \%)$ & $40(11 \%)$ & $26(7.3 \%)$ & \\
\hline III & $173(24.0 \%)$ & 76 (20.9\%) & $97(27.1 \%)$ & \\
\hline IV & $47(6.5 \%)$ & $15(4.1 \%)$ & $32(8.9 \%)$ & \\
\hline V & $29(4.0 \%)$ & $19(5.2 \%)$ & $10(2.8 \%)$ & \\
\hline \multicolumn{5}{|l|}{ Liver } \\
\hline No liver injury & $277(38.4 \%)$ & $120(33.0 \%)$ & $157(43.9 \%)$ & \multirow[t]{7}{*}{0.096} \\
\hline । & $43(6 \%)$ & $21(5.8 \%)$ & $22(6.1 \%)$ & \\
\hline$\|$ & $97(13.4 \%)$ & $52(14.3 \%)$ & $45(12.6 \%)$ & \\
\hline III & $221(30.6 \%)$ & $124(34.1 \%)$ & $97(27.1 \%)$ & \\
\hline IV & $66(9.1 \%)$ & $37(10.2 \%)$ & $29(8.1 \%)$ & \\
\hline V & $17(2.4 \%)$ & $9(2.5 \%)$ & $8(2.2 \%)$ & \\
\hline $\mathrm{Vl}$ & $1(0.1 \%)$ & $1(0.3 \%)$ & $0(0 \%)$ & \\
\hline \multicolumn{5}{|l|}{$\begin{array}{l}\text { Associated extra-abdominal } \\
\text { injuries (AIS } \geq 1 \text { ) }\end{array}$} \\
\hline Head or neck & $267(36.5 \%)$ & $173(46.5 \%)$ & $94(26.2 \%)$ & $<0.001$ \\
\hline Face & $101(13.8 \%)$ & $52(14 \%)$ & 49 (13.6\%) & 0.897 \\
\hline Chest & $463(63.3 \%)$ & $270(72.6 \%)$ & $193(53.8 \%)$ & $<0.001$ \\
\hline Extremities or pelvic girdle & $342(46.8 \%)$ & $203(54.6 \%)$ & $139(38.7 \%)$ & $<0.001$ \\
\hline External (skin and soft tissue) & $457(62.5 \%)$ & 291 (78.2\%) & 166 (46.2\%) & $<0.001$ \\
\hline
\end{tabular}

ISS Injury Severity Score, AAST American Association for the Surgery of Trauma, AIS Abbreviated Injury Score 
Table 3 Management of blunt hepatic and splenic injuries

\begin{tabular}{|c|c|c|c|c|}
\hline & $\begin{array}{l}\text { Overall cohort (2000- } \\
2016) \\
n=731\end{array}$ & $\begin{array}{l}\text { Early period (2000- } \\
2008) \\
n=372\end{array}$ & $\begin{array}{l}\text { Late period (2009- } \\
\text { 2016) } \\
n=359\end{array}$ & $\begin{array}{l}\text { Difference between } \\
\text { periods } \\
P\end{array}$ \\
\hline \multicolumn{5}{|l|}{ Primary therapy } \\
\hline $\mathrm{OM}$ & $127(17.4 \%)$ & $69(18.5 \%)$ & $58(16.2 \%)$ & \multirow[t]{2}{*}{0.393} \\
\hline NOM & $604(82.6 \%)$ & $303(81.5 \%)$ & $301(83.8 \%)$ & \\
\hline \multicolumn{5}{|l|}{ NOM rate according to the injured organ } \\
\hline NOM splenic injury & $201(71.8 \%)$ & $85(69.1 \%)$ & $116(73.9 \%)$ & 0.378 \\
\hline NOM hepatic injury & $344(93.5 \%)$ & $177(92.2 \%)$ & $167(94.9 \%)$ & 0.295 \\
\hline NOM combined splenic and hepatic injury & $59(71.1 \%)$ & $41(71.9 \%)$ & $18(69.2 \%)$ & 0.801 \\
\hline \multicolumn{5}{|l|}{ Surgical procedures (\% of all patients) } \\
\hline \multicolumn{5}{|l|}{ Spleen } \\
\hline Complete splenectomy & $79(10.8 \%)$ & $41(11 \%)$ & $38(10.6 \%)$ & \multirow[t]{2}{*}{0.966} \\
\hline $\begin{array}{l}\text { Spleen-conserving procedures (suture, hemostasis, } \\
\text { etc.) }\end{array}$ & $17(2.3 \%)$ & $9(2.4 \%)$ & $8(2.2 \%)$ & \\
\hline \multicolumn{5}{|l|}{ Liver } \\
\hline Hepatic partial resection & $8(1.1 \%)$ & $5(1.3 \%)$ & $3(0.8 \%)$ & \multirow[t]{2}{*}{0.113} \\
\hline Liver-conserving procedure (suture, hemostasis, etc.) & $34(4.7 \%)$ & $23(6.2 \%)$ & $11(3.1 \%)$ & \\
\hline Angiography or ERCP in case of primary NOM & $9(1.2 \%)$ & $2(0.5 \%)$ & $7(2.0 \%)$ & 0.194 \\
\hline Failure NOM (secondary operative, \% of NOM) & $20(3.3 \%)$ & $11(3.6 \%)$ & $9(3 \%)$ & 0.515 \\
\hline \multicolumn{5}{|l|}{ Cause for the failure of NOM (\% of all NOM) } \\
\hline $\begin{array}{l}\text { Persistent or secondary bleeding/hemodynamic } \\
\text { instability }\end{array}$ & $13(65 \%)$ & $5(45.5 \%)$ & $8(88.9 \%)$ & \multirow[t]{3}{*}{0.123} \\
\hline $\begin{array}{l}\text { Extent of intra-abdominal hematoma (compression/ } \\
\text { compartment) }\end{array}$ & $5(25 \%)$ & $4(36.4 \%)$ & $1(11.1 \%)$ & \\
\hline Infectious complications (bile duct injury, sepsis, MOF) & $2(10 \%)$ & $3(18.2 \%)$ & $0(0 \%)$ & \\
\hline \multicolumn{5}{|l|}{ Management of failed NOM (\% of all failed NOM) } \\
\hline Splenectomy & $11(55 \%)$ & $5(45.5 \%)$ & $6(66.7 \%)$ & \multirow[t]{4}{*}{0.517} \\
\hline Spleen-conserving surgery & $2(10 \%)$ & $2(18.2 \%)$ & $0(0 \%)$ & \\
\hline Liver resection & $3(15 \%)$ & $1(9.1 \%)$ & $2(22.2 \%)$ & \\
\hline Non-resection liver surgery (suture, hemostatics, etc.) & $4(20 \%)$ & $3(27.3 \%)$ & 1 (11.1\%) & \\
\hline
\end{tabular}

OM operative management, NOM non-operative management, ERCP endoscopic retrograde cholangiopancreatography, SD standard deviation, $M O F$ multiorgan failure

patients (37\%), no recordings of associated findings were available in our records.

NOM was successful in 584 patients $(96.7 \%$ of NOM cases). Twenty failures (3.3\%) were observed, and this rate was consistent over 17 years ( $p=$ 0.515). Underlying causes for NOM failure did change over time with the most relevant cause being hemodynamic instability due to persistent or secondary bleeding lately $(90 \%$ compared to previously $45.5 \%$ ); however, this was not statistically significant $(p=0.123)$. The management for failure of NOM patients included splenectomy (55\%), spleenconserving surgery (10\%), liver resection (15\%), and non-resecting liver surgery $(20 \%)$ including suture $(n=1)$ and hemostatics $(n=3)$.

\section{Outcome of trauma patients (Table 4)}

Median duration of hospital stay was 14 days (SD 20.2) with a range of $0-382$ days, significantly decreasing from 16 to 13 days in the recent period $(p<0.001)$.

Overall mortality in the study cohort was $4.8 \%$, with $11 \%$ in the surgery group and $3.5 \%$ in the NOM group. Mortality in failure of NOM patients was $0 \%$ compared to $3.6 \%(n=21)$ in patients without failure of NOM. Over time, a significant decrease in overall mortality (7.5 to $1.9 \% ; p<0.001)$ and mortality in the conservatively managed subgroup (from 5.6 to $1.3 \%, p=0.006$ ) was confirmed by our analysis. While an even more pronounced improvement in mortality was noted in the operative group between the two study periods (15.9 to $5.2 \%)$, this did just not reach statistical significance ( $p=$ 
Table 4 Outcomes of treatment for blunt hepatic and splenic injuries

\begin{tabular}{|c|c|c|c|c|}
\hline \multicolumn{5}{|l|}{ Length of hospital stay (days, missing $=4$ ) } \\
\hline Median (range) & $14(0-382)$ & $16(0-382)$ & $13(0-112)$ & $<0.001$ \\
\hline In-hospital mortality (\% of all patients) & $35(4.8 \%)$ & $28(7.5 \%)$ & $7(1.9 \%)$ & $<0.001$ \\
\hline Mortality of primary NOM patients & $21(3.5 \%)$ & $17(5.6 \%)$ & $4(1.3 \%)$ & 0.006 \\
\hline Mortality of primary surgical patients & $14(11 \%)$ & $11(15.9 \%)$ & $3(5.2 \%)$ & 0.086 \\
\hline \multicolumn{5}{|l|}{ Cause of death (\% of deaths) } \\
\hline Sepsis & $7(20 \%)$ & $7(25 \%)$ & $0(0 \%)$ & \multirow[t]{7}{*}{0.436} \\
\hline Hemorrhagic shock & $3(8.6 \%)$ & $3(10.7 \%)$ & $0(0 \%)$ & \\
\hline Intracranial hypertension & $11(31.4 \%)$ & $8(28.6 \%)$ & $3(42.9 \%)$ & \\
\hline Multiorgan failure & $5(14.3 \%)$ & $3(10.7 \%)$ & $2(28.6 \%)$ & \\
\hline Cardiac dysfunction/infarction & $1(2.9 \%)$ & $1(3.6 \%)$ & $0(0 \%)$ & \\
\hline Arrived with CPR, no ROSC & $6(17.1 \%)$ & $5(17.9 \%)$ & $1(14.3 \%)$ & \\
\hline Other/unknown & $2(5.7 \%)$ & 1 (3.6\%) & 1 (14.3\%) & \\
\hline
\end{tabular}

$C P R$ cardiopulmonary resuscitation, $R O S C$ return of spontaneous circulation

0.086), primarily owed to the limited number of OM patients in both groups.

Most frequent cause of death was uncontrollable intracranial hypertension in 11 (31.4\%) patients, followed by septic shock $(n=7,20 \%)$, and no return of spontaneous circulation (ROSC) after cardiopulmonary resuscitation (CPR) on arrival.

To compare outcomes of blunt hepatic or splenic injury patients with our overall emergency care outcome, we further assessed the number of total injury-related admissions to our emergency room and the respective death rate over time (available from 2007 to 2016). During three equal periods, the mortality decreased from $7.6 \%(n=136 / 1791)$ in $2007-2010$ to $6.8 \% \quad(n=125 /$ $1843)$ in $2011-2013$ and $6.3 \%(109 / 1724)$ in the recent time-period (2014-2016); however, with no statistical significance $(p=0.321)$. While admission rates remain constant, this accounts for an absolute decrease in mortality of $1.3 \%$ over 10 years (17\% relative risk reduction).

\section{Differences over time between operative and non- operative managed patients}

Changes in patient characteristics and management details of OM and NOM over the two periods are summarized in Table 5. Regarding ISS comparing OM and NOM patients, a significant difference was observed in the early period $(p=0.046)$, while the severity of the injury was identical between NOM and OM cases recently $(p=0.507)$. Also, relevant differences in the management of blunt injuries were registered over both periods: OM was mostly applied in isolated splenic trauma, while isolated liver injuries were primarily treated with NOM $(p<0.001)$ in both periods. Significant differences concerning performed therapy according to the severity of organ injury were detected: in both periods, high-grade splenic injuries were mostly treated with operative therapy. In patients with liver trauma however, the rate of high-grade injuries requiring operative management decreased over time from 19.5 to $10.5 \%$. We furthermore analyzed the differences in the success of NOM between patients with low-grade (AAST I-III) versus high-grade $(\geq$ IV) splenic and/or liver injuries over time. In the whole observation period, failure of NOM occurred in $2 \%$ of low-grade injuries compared to $10.4 \%$ in highgrade injuries $(p<0.001)$. Interestingly, the rate was $1.9 \%$ versus $13.3 \%$ in the early period $(p<0.001)$ compared to $2 \%$ versus $7.8 \%(p=0.048)$ in the late period.

\section{Discussion}

This analysis is characterized by three main points: (I) the observed cohort represents one of the largest Western European single-center experiences available, reporting clinical presentations, management, and outcomes of blunt liver and splenic injuries over a time span of 17 years; (II) NOM was the option of treatment in more than $80 \%$ of cases with only minor changes over time; and (III) injury severity decreased over time accompanied by major improvements in mortality rates.

The mechanisms of liver and splenic injuries vary geographically due to community factors [26]. Compared to other continents, blunt abdominal trauma comprises most of the injuries in the EU and typically results from a motor vehicle collision or a fall, while penetrating injuries as a result of bullet or knife assaults account for a minimal amount of trauma. In contrast to other national studies, where the rate of blunt abdominal injuries is high secondary to the increasing trend of motor vehicles [26], in Austria, traffic collisions declined in the last years (Fig. 1a). In contrast, a growing number of polytrauma caused by recreational activities were registered over the recent decades (Fig. 1b) [17]. From 2002 to 2014 , overall injury rate increased about $12.3 \%$, and in 
Table 5 Differences between operative $(\mathrm{OM})$ and non-operative managed (NOM) patients in the two periods

\begin{tabular}{|c|c|c|c|c|c|c|}
\hline & \multicolumn{3}{|c|}{ Early period (2000-2008) } & \multicolumn{3}{|c|}{ Late period (2009-2016) } \\
\hline & $\begin{array}{l}\text { OM patients } \\
n=69\end{array}$ & $\begin{array}{l}\text { NOM patients } \\
n=303\end{array}$ & $P$ & $\begin{array}{l}\text { OM patients } \\
n=58\end{array}$ & $\begin{array}{l}\text { NOM patients } \\
n=301\end{array}$ & $P$ \\
\hline Male & $52(75.4 \%)$ & $199(65.7 \%)$ & 0.121 & $40(69.0 \%)$ & $206(68.4 \%)$ & 0.937 \\
\hline Age (median, SD) & $31.8(17.2)$ & $26.5(17.9)$ & 0.087 & 34.5 (17.9) & $29.0(18.5)$ & 0.355 \\
\hline \multicolumn{7}{|l|}{ Trauma cause $($ missing $=2$ ) } \\
\hline Car collision & $16(23.2 \%)$ & $85(28.2 \%)$ & 0.518 & $9(15.5 \%)$ & $46(15.3 \%)$ & 0.322 \\
\hline Motorcycle collision & $15(21.7 \%)$ & $31(10.3 \%)$ & & $6(10.3 \%)$ & $35(11.6 \%)$ & \\
\hline Pedestrian or occupational collision & $4(5.8 \%)$ & $22(7.3 \%)$ & & $2(3.4 \%)$ & $7(2.3 \%)$ & \\
\hline Cycling collision & $5(7.2 \%)$ & $19(6.3 \%)$ & & $2(3.4 \%)$ & $36(12.0 \%)$ & \\
\hline Winter sports & $15(21.7 \%)$ & $77(25.6 \%)$ & & $26(44.8 \%)$ & $124(41.2 \%)$ & \\
\hline Fall from heights & $8(11.6 \%)$ & $41(13.6 \%)$ & & $6(10.3 \%)$ & $21(7.0 \%)$ & \\
\hline Trauma in homely environment & $4(5.8 \%)$ & $16(5.3 \%)$ & & $7(12.1 \%)$ & $20(6.6 \%)$ & \\
\hline Personal assault & $0(0 \%)$ & $1(0.3 \%)$ & & $0(0 \%)$ & $2(0.7 \%)$ & \\
\hline Horse riding collision (and other animals) & $2(2.9 \%)$ & $9(3.0 \%)$ & & $0(0 \%)$ & $10(3.3 \%)$ & \\
\hline Glasgow Coma Scale (GCS) on admission $\leq 8$ & $20(29 \%)$ & $56(18.7 \%)$ & 0.058 & $5(8.9 \%)$ & $25(8.5 \%)$ & 0.923 \\
\hline Injury Severity Score (ISS) > 15 & $67(97.1 \%)$ & $271(89.4 \%)$ & 0.046 & $44(75.9 \%)$ & $240(79.7 \%)$ & 0.507 \\
\hline \multicolumn{7}{|l|}{ Injured organ } \\
\hline Spleen & $38(55.1 \%)$ & $85(28.1 \%)$ & $<0.001$ & $41(70.7 \%)$ & $116(38.5 \%)$ & $<0.001$ \\
\hline Liver & $15(21.7 \%)$ & $177(58.4 \%)$ & & $9(15.5 \%)$ & $167(55.5 \%)$ & \\
\hline Combined liver and spleen injury & $16(23.2 \%)$ & $41(13.5 \%)$ & & $8(13.8 \%)$ & $18(6 \%)$ & \\
\hline \multicolumn{7}{|l|}{ AAST (Moore) Injury Score (missing = 9) } \\
\hline \multicolumn{7}{|l|}{ Spleen } \\
\hline No spleen injury & $15(24.2 \%)$ & $177(58.6 \%)$ & $<0.001$ & $8(14 \%)$ & $167(55.5 \%)$ & $<0.001$ \\
\hline$|-|||$ & $23(37.1 \%)$ & $115(38.1 \%)$ & & $27(47.4 \%)$ & $114(37.9 \%)$ & \\
\hline IV-V & $24(38.7 \%)$ & $10(3.3 \%)$ & & $22(38.6 \%)$ & $20(6.6 \%)$ & \\
\hline \multicolumn{7}{|l|}{ Liver } \\
\hline No liver injury & $36(58.1 \%)$ & $84(27.8 \%)$ & $<0.001$ & $41(71.9 \%)$ & $116(38.5 \%)$ & $<0.001$ \\
\hline$|-|||$ & $14(22.6 \%)$ & $183(60.6 \%)$ & & $10(17.5 \%)$ & $154(51.2 \%)$ & \\
\hline$|V-V|$ & $12(19.4 \%)$ & $35(11.6 \%)$ & & $6(10.5 \%)$ & $31(10.3 \%)$ & \\
\hline \multicolumn{7}{|l|}{ Associated extra-abdominal injuries (AIS $\geq 1$ ) } \\
\hline Head or neck & $35(50.7 \%)$ & $138(45.5 \%)$ & 0.436 & $12(20.7 \%)$ & $82(27.2 \%)$ & 0.299 \\
\hline Face & $10(14.5 \%)$ & $42(13.9 \%)$ & 0.891 & $5(8.6 \%)$ & $44(14.6 \%)$ & 0.223 \\
\hline Chest & 49 (71\%) & $221(72.9 \%)$ & 0.747 & $35(60.3 \%)$ & $158(52.5 \%)$ & 0.272 \\
\hline Extremities or pelvic girdle & $44(63.8 \%)$ & $159(52.5 \%)$ & 0.089 & $22(37.9 \%)$ & $117(38.9 \%)$ & 0.893 \\
\hline External (skin and soft tissue) & $57(82.6 \%)$ & $234(77.2 \%)$ & 0.328 & $30(51.7 \%)$ & $136(45.2 \%$ & 0.360 \\
\hline
\end{tabular}

OM operative management, NOM non-operative management, SD standard deviation, ISS Injury Severity Score, AAST American Association for the Surgery of Trauma, AIS Abbreviated Injury Score, GCS Glasgow Coma Scale

contrast, death rate decreased about $16.4 \%$ [16]. Previous studies showed that concerning sport activities, most injuries occurred by practicing soccer or winter sports [18].

This was also confirmed by the present analysis were currently winter sports are responsible for more than $40 \%$ of splenic or hepatic injuries, by far representing the major trauma mechanism in patients admitted to our center. The persisting large number of severe winter sports accidents in our catchment area might be explained by dramatic increases of tourism accompanied by over-crowded slopes and additional aggravation through the invention of new high-speed sports equipment such as carving skies. Simultaneously, for example, head protection gear is still not mandatory above the age of 15 in our state.

In terms of injury severity, we observed a significant reduction over time through several parameters including ISS, GCS, and organ involvement patterns. Alongside 
improved medical, surgical, and intensive care trauma treatment in our center, we believe that nationwide safety measures are substantially responsible for this trend resulting in markedly reduced regional and national trauma mortality (Fig. 1a, b) [18].

In our study, the overall mortality rate was $4.8 \%(11 \%$ in the OM group and $3.5 \%$ in the NOM group), and most deaths were due to extensive concomitant extraabdominal injuries, resulting in a subsequent septic shock or unmanageable intracranial hypertension. The mortality rate in the whole cohort as well as in the NOM subgroup decreased significantly over the study period ( 7.5 to $1.9 \%$ and 5.6 to $1.3 \%$, respectively), a similar trend was observed in the operative group (15.9 to $5.2 \%)$, although closely not statistically significant ( $p=$ 0.086). Our results are in line with other published data showing overall mortality rates around 3.5\% [27].

According to data from the World Health Organization (WHO), 1.24 million road traffic deaths occur every year, differing widely between individual continents. In the African continent, the highest rate (24.1 per million population) is described, while in South-East Asia and Western Pacific 18.5 deaths per million are counted. The American and European continents are still the safest regions with 16.1 and 10.3 deaths per million, respectively. Simultaneous to the development of the newest medical therapies, the introduction of national safety measures dramatically contributed to a relevant decline of road and sports collisions. As an example, $5 \%$ cut in average speed can result in $30 \%$ reduction of fatal crashes, as well as wearing a motorcycle helmet correctly ends in $40 \%$ reduction of death risk. Finally, seat belts reduce the risk of a fatal injury in 50-75\% [28]. The effect of such legislations moderated the injury grade and the involvement of extraabdominal regions, ameliorating the injury prognosis.

Regarding trauma management, previous studies demonstrated that around $80 \%$ of patients with hepatic or splenic injuries can successfully be treated conservatively [2]. Reported failure rates reached from 3 to $10 \%$ and were mainly secondarily to delayed bleeding, hematoma, and associated injuries [26]. In line with this, our results showed 96.7\% NOM success rate. Failure of NOM amounts to $3.3 \%$ over the study period, caused by hemodynamic instability due to persistent or secondary bleeding. These outcomes, in view of a significant decrease in mortality in conservatively treated patients (from 5.6 to 1.3\%), indicate an improved utilization of the NOM approach as compared to initial series where $60 \%$ of cases were treated conservatively with a subsequent failure rate of $15 \%$ [29]. Modern coagulation management, including thromboelastography to guide blood product resuscitation, contributed to improved outcomes for NOM at our center. According to an Austrian survey in 2016, the rate of NOM was $>50 \%$ in more than two thirds of all national hospitals and an increasing trend towards radiologic interventions was reported [30].

In the present study, $17.4 \%$ of cases underwent OM due to hemodynamic instability. Co-factors included high injury score and multiple abdominal injuries. Notably, OM was primarily applied in high-grade splenic injuries over the whole study period and high-grade liver injuries in the early period, while major hepatic injuries in the late period were treated equally with OM and NOM (10.5\% vs $10.3 \%)$ . With ongoing specialization and more complex procedures in liver surgery showing its unique regeneration potential, more conservative approaches even in higher grade liver injuries were utilized. Moreover, a detailed radiological scoring system (AAST) has given us the ability to characterize injury severity more precisely. However, the AAST-Moore-Classification does not incorporate the full spectrum of vascular injuries and might therefore be of less value. The Baltimore CT severity index (CTSI) for splenic injuries tries to overcome this limitation and allows for direct correlation of vascular CT imaging characteristics and choice of patient clinical management [31]. The purpose and validation of a similar score for liver injuries are currently under development at our institution.

Although most solid organ injuries can be treated with NOM, mainly due to improvement in overall interdisciplinary trauma management, the ones that required surgery in our unit did so emergently, carrying a high risk of morbidity and mortality if appropriate surgical treatment is delayed. In order to further raise the rate of splenic NOM management, increased application of interventional radiology may be a key feature. In contrast with the increasing utilization in other level I trauma centers, in our series, angiography or ERCP were applied in a low number of only $1.2 \%$ in case of primary $\mathrm{NOM}$, showing a clear potential for improvement. Overcoming the limited experience of the last years, however, these techniques have gained expertise and acceptance recently at our center. Interventional radiology techniques, especially in case of contrast extravasation, were previously described as important diagnostic and therapeutic tools in a relevant number of patients with blunt liver and splenic injuries to improve NOM success rates and reduce avoidable operations [9, 32, 33]. The organ salvage rate ranges from 86 to $100 \%$, with success rates $>90 \%$ in splenic injuries and between $79 \%$ and $92 \%$ in liver injuries by using arterial embolization [34-36]. Even if morbidity and complication rates like re-bleeding should be considered after angiography [9], further improvements in overall mortality by increased implementation of these techniques and modern coagulation management could be expected in our center [37, 38].

There were several limitations to the current study, mostly due to the retrospective study design. For example, 
detailed information regarding concomitant injured abdominal organs, as well as operation times, post-operative complications, and follow-up post-discharge were not recorded systematically and would be of interest in further prospective studies. Additionally, the RTS classification was excluded from data analysis because of a large number of missing hemodynamic variables. Furthermore, pre-hospital or on admission death patients were not included in this analysis which may underestimate the regional on-site mortality rate due to blunt trauma. Finally, the strict focus on local patients with hepatic and splenic injuries may limit the ability to extrapolate our results to overall changes of injury rates and trauma outcomes on a broader level. However, by implementing national trauma data as well as overall hospital emergency admission data, we have aimed to further strengthen our conclusions. This analysis represents one of the largest singlecenter experiences on blunt hepatic and splenic injuries performed over a long study period to be reported in Western Europe. Besides systematically re-evaluated radiological reports, it includes extensive data on injury patterns, surgical, and NOM details as well as outcome parameters and therefore clearly improves available knowledge in this specific subject.

\section{Conclusion}

The present study confirmed the effectiveness of NOM in patients with liver and splenic injuries, suggesting a safe and effective therapeutic approach, with recent overall mortality rates below $2 \%$. According to these findings, the majority of patients can be treated with NOM in a less invasive manner, avoiding unnecessary laparotomies, which is particularly true in liver injuries with recent NOM rates surpassing 95\%. Although surgery is nowadays only applied in about one third of splenic injury patients in our center, these numbers might further decrease by intensified application of interventional radiology. Overall, national and regional safety measures resulted in a significantly decreased severity of observed injury patterns and deaths due to blunt hepatic or splenic trauma. Further prospective studies in high-volume centers or on a national level including analysis of pre-hospital management and systematic implementation of interventional radiology would be desirable to validate these findings and further improve patient care.

\section{Additional files}

Additional file 1: Table S1. Moore classification/AAST liver injury scale [1]. (DOCX $17 \mathrm{~kb})$

Additional file 2: Table S2. Moore classification/AAST spleen injury scale [1]. (DOCX $17 \mathrm{~kb})$

\section{Abbreviations}

AAAM: American Association for Automotive Medicine; AAST: American Association for Surgery of Trauma; AIS: Abbreviated Injury Score; CPR: Cardiopulmonary Resuscitation; CTSI: CT severity index;

ERCP: Endoscopic retrograde cholangiopancreatography; EU: European Union; GCS: Glasgow Coma Score; ISS: Injury Severity Score; LOS: Length of hospital stay; NOM: Non-operative management; OM: Operative management; ROSC: Return of spontaneous circulation

\section{Acknowledgements}

Not applicable

\section{Authors' contributions}

MF, FP, and SS contributed to the conceptualization and design. MF, FP, DM, $\mathrm{VK}, \mathrm{AP}, \mathrm{MH}, \mathrm{SS}$, and UN contributed to the data acquisition and curation; MF, FP, DM, EG, UN, DÖ, and SS contributed to the data analysis. MF, FP, SS, and UN contributed to the data interpretation. MF, FP, VK, AP, and UN contributed to the investigation. MF, FP, and SS contributed to the methodology. FP and SS contributed to the project coordination. SS and DÖ contributed to the resources. FP, SS, DÖ, UN, EB, MH, and MB contributed to visualization. MF, FP, and VK contributed to the writing-draft preparation. $M F, F P, V K, S S, D O ̈$, and MB contributed to the writing-review and editing. All authors read and approved the final manuscript.

\section{Funding}

Not applicable

Availability of data and materials

All data generated or analyzed during this study are included in this published article and its supplementary information files.

Ethics approval and consent to participate

Not applicable

Consent for publication

Not applicable

\section{Competing interests}

The authors declare that they have no competing interests.

\section{Author details}

'Department of Visceral, Transplantation and Thoracic Surgery, Center of Operative Medicine, Medical University of Innsbruck, Anichstraße 35, 6020 Innsbruck, Austria. ${ }^{2}$ Department of Radiology, Medical University of Innsbruck, Innsbruck, Austria. ${ }^{3}$ Department of Trauma Surgery, Center of Operative Medicine, Medical University of Innsbruck, Innsbruck, Austria. ${ }^{4}$ Department of Surgery, Klinikum Rechts der Isar, Technical University of Munich, Munich, Germany. ${ }^{5}$ Department of General and Surgical Intensive Care Medicine, Medical University of Innsbruck, Innsbruck, Austria.

Received: 22 March 2019 Accepted: 4 June 2019

Published online: 17 June 2019

\section{References}

1. Fodor M, Primavesi F, Morell D, Haselbacher M, Braunwarth E, Cardini B, et al. Non-operative management of blunt hepatic and splenic injuriespractical aspects and value of radiological scoring systems. Eur Surg. 2018; 50(6):285-98,

2. Raza M, Abbas Y, Devi V, Prasad KV, Rizk KN, Nair PP. Non operative management of abdominal trauma - a 10 years review. World J Emerg Surg. 2013;8:14.

3. Coccolini F, Montori G, Catena F, Di Saverio S, Biffl W, Moore EE, et al. Liver trauma: WSES position paper. World J Emerg Surg. 2015;10:39.

4. Coccolini F, Montori G, Catena F, Kluger Y, Biffl W, Moore EE, et al. Splenic trauma: WSES classification and guidelines for adult and pediatric patients. World J Emerg Surg. 2017;12:40.

5. Lucciarini $P$, Ofner D, Weber F, Lungenschmid D. Ultrasonography in the initial evaluation and follow-up of blunt abdominal injury. Surgery. 1993;114(3):506-12.

6. Beuran M, Negoi I, Păun S, Runcanu A, Venter D, lordache F, et al. Selective nonoperative management of solid abdominal visceral lesionsChirurgia (Bucur). 2010;105(3):317-26. 
7. van der Vlies CH, Olthof DC, Gaakeer M, Ponsen KJ, van Delden OM, Goslings JC. Changing patterns in diagnostic strategies and the treatment of blunt injury to solid abdominal organs. Int J Emerg Med. 2011;4:47.

8. Stawicki SP. Trends in nonoperative management of traumatic injuries - a synopsis. Int J Crit IIIn Inj Sci. 2017;7(1):38-57.

9. Olthof DC, Joosse P, van der Vlies $\mathrm{CH}$, de Haan RJ, Goslings JC. Prognostic factors for failure of nonoperative management in adults with blunt splenic injury: a systematic review. J Trauma Acute Care Surg. 2013;74(2):546-57.

10. Olthof DC, Lammers AJ, van Leeuwen EM, Hoekstra JB, ten Berge IJ, Goslings JC. Antibody response to a T-cell-independent antigen is preserved after splenic artery embolization for trauma. Clin Vaccine Immunol. 2014;21(11):1500-4.

11. Cirocchi R, Boselli C, Corsi A, Farinella E, Listorti C, Trastulli S, et al. Is nonoperative management safe and effective for all splenic blunt trauma? A systematic review. Crit Care. 2013;17(5):R185.

12. Cirocchi R, Trastulli S, Pressi E, Farinella E, Avenia S, Morales Uribe CH, et al. Non-operative management versus operative management in high-grade blunt hepatic injury. Cochrane Database Syst Rev. 2015;(8):CD010989. https://doi.org/10.1002/14651858.CD010989.pub2

13. Boese CK, Hackl M, Müller LP, Ruchholtz S, Frink M, Lechler P. Nonoperative management of blunt hepatic trauma: a systematic review. J Trauma Acute Care Surg. 2015;79(4):654-60.

14. Austria S. Statistik Austria https:/www.statistik.at/web_de/statistiken/index.html.

15. Transport Ma. https:/ec.europa.eu/transport/road_safety/specialist/statistics_en.

16. Austria ID. Injury database Austria. 2019.

17. Ruedl G, Bilek H, Ebner H, Gabl K, Kopp M, Burtscher M. Fatalities on Austrian ski slopes during a 5-year period. Wilderness Environ Med. 2011;22(4):326-8.

18. Österreich KUUliMi. KFV Unfallbilanz 2017: Unfälle im Minutentakt in Österreich.

19. Fries $D$, Innerhofer $P$, Perger $P$, Gütl M, Heil S, Hofmann N, et al. Coagulation management in trauma-related massive bleeding. - Recommendations of the Task Force for Coagulation (AGPG) of the Austrian Society of Anesthesiology, Resuscitation and Intensive Care Medicine (OGARI). Anasthesiol Intensivmed Notfallmed Schmerzther. 2010;45(9):552-61.

20. Schöchl H, Nienaber U, Maegele M, Hochleitner G, Primavesi F, Steitz B, et al. Transfusion in trauma: thromboelastometry-guided coagulation factor concentrate-based therapy versus standard fresh frozen plasma-based therapy. Crit Care. 2011;15(2):R83.

21. Moore EE, Shackford SR, Pachter HL, McAninch JW, Browner BD, Champion HR, et al. Organ injury scaling: spleen, liver, and kidney. J Trauma. 1989:29(12):1664-6.

22. Abajas Bustillo R, Leal Costa C, Ortego Mate MDC, Zonfrillo MR, Seguí Gómez M, Durá Ros MJ. Classification of the severe trauma patient with the Abbreviated Injury Scale: degree of correlation between versions 98 and 2005 (2008 update). Emergencias. 2018;30(1):41-4.

23. Gennarelli TA, Wodzin E. AIS 2005: a contemporary injury scale. Injury. 2006;37(12):1083-91.

24. Baker SP, O'Neill B, Haddon W, Long WB. The Injury Severity Score: a method for describing patients with multiple injuries and evaluating emergency care. J Trauma. 1974;14(3):187-96.

25. von Elm E, Altman DG, Egger M, Pocock SJ, Gøtzsche PC, Vandenbroucke JP, et al. The Strengthening the Reporting of Observational Studies in Epidemiology (STROBE) statement: guidelines for reporting observational studies. Rev Esp Salud Publica. 2008;82(3):251-9.

26. Afifi I, Abayazeed S, El-Menyar A, Abdelrahman H, Peralta R, Al-Thani H. Blunt liver trauma: a descriptive analysis from a level I trauma center. BMC Surg. 2018;18(1):42.

27. Ghnnam WM, Almasry HN, Ghanem MA. Non-operative management of blunt liver trauma in a level II trauma hospital in Saudi Arabia. Int J Crit IIIn Inj Sci. 2013;3(2):118-23.

28. www.who.int/violence_injury_prevention/road_safety_status [Internet]. Available from: https://www.who.int/violence_injury_prevention/road_ safety_status/2013/facts/en/. 2013

29. Bernardo CG, Fuster J, Bombuy E, Sanchez S, Ferrer J, Loera MA, et al. Treatment of liver trauma: operative or conservative management. Gastroenterology Res. 2010;3(1):9-18.

30. Fodor M. Management of blunt hepatic and splenic trauma in Austria: a national questionnaire study; 2019.
31. Marmery H, Shanmuganathan K, Mirvis SE, Richard H, Sliker C, Miller LA, et al. Correlation of multidetector $\mathrm{CT}$ findings with splenic arteriography and surgery: prospective study in 392 patients. J Am Coll Surg. 2008;206(4):685-93.

32. Brillantino A, lacobellis F, Festa P, Mottola A, Acampora C, Corvino F, et al. Non-operative management of blunt liver trauma: safety, efficacy and complications of a standardized treatment protocol. Bull Emerg Trauma. 2019;7(1):49-54.

33. Saltzherr TP, van der Vlies $\mathrm{CH}$, van Lienden KP, Beenen LF, Ponsen KJ, van Gulik TM, et al. Improved outcomes in the non-operative management of liver injuries. HPB (Oxford). 2011;13(5):350-5.

34. Malhotra AK, Latifi R, Fabian TC, Ivatury RR, Dhage S, Bee TK, et al. Multiplicity of solid organ injury: influence on management and outcomes after blunt abdominal trauma. J Trauma. 2003;54(5):925-9.

35. Pachter HL, Knudson MM, Esrig B, Ross S, Hoyt D, Cogbill T, et al. Status of nonoperative management of blunt hepatic injuries in 1995: a multicenter experience with 404 patients. J Trauma. 1996;40(1):31-8.

36. van der Vlies $\mathrm{CH}$, Hoekstra J, Ponsen KJ, Reekers JA, van Delden OM, Goslings JC. Impact of splenic artery embolization on the success rate of nonoperative management for blunt splenic injury. Cardiovasc Intervent Radiol. 2012;35(1):76-81.

37. Fries $D$, Innerhofer $P, S p a h n D R$. Transfusion approaches and mortality in trauma patients: a narrative review. Semin Thromb Hemost. 2017:43(7):759-71.

38. Innerhofer P, Fries D, Oswald E, Group Rs. Early fibrinogen-concentrate administration in management of trauma-induced coagulopathy - Authors' reply. Lancet Haematol. 2017;4(8):e348-e9.

\section{Publisher's Note}

Springer Nature remains neutral with regard to jurisdictional claims in published maps and institutional affiliations.

\section{Ready to submit your research? Choose BMC and benefit from:}

- fast, convenient online submission

- thorough peer review by experienced researchers in your field

- rapid publication on acceptance

- support for research data, including large and complex data types

- gold Open Access which fosters wider collaboration and increased citations

- maximum visibility for your research: over $100 \mathrm{M}$ website views per year

At BMC, research is always in progress.

Learn more biomedcentral.com/submissions 